\title{
Review
}

\section{Reason in a dark time: Why the struggle against climate change failed - And what it means for our future}

\author{
Dale Jamieson \\ Oxford University Press, Oxford, 2014, xvi+266pp., ISBN: 978-0199337668
}

Contemporary Political Theory (2017) 16, 155-157. doi:10.1057/cpt.2015.62;

advance online publication 24 November 2015

This fine book is a post-mortem. The dream that the world would unite to prevent climate change is dead, and Jamieson wants to know what killed it. Much has been written about the ethics, the psychology and the politics of climate change. This is not the very best book that has been written on any one of those subjects, but it may be the best synthesis of the three taken together, and as such will make an excellent text for graduate and advanced undergraduate classes. At the same time, it is also a search for lessons: We may not be able to stop climate change, but we can still make it better or worse. Jamieson's diagnosis of the problem is acute, and his advice is generally sound.

In a way, it is strange that we are still arguing over climate change. Scientists agree it is happening, and to prevent the worst effects would not be terribly costly - perhaps 1 or 2 per cent of GDP. Why not stop yammering and just do it? One reason, Jamieson suggests, is that we find it hard to believe that transforming our energy supply could really be that cheap. The late twentieth-century transition from analogue to digital technology also involved sweeping changes that were not in the end very burdensome: "while people incurred expenses in replacing analogue devices and in reorganizing their lives, the forces driving this innovation were so powerful and the benefits so palpable that the economic and social obstacles were overwhelmed' (p. 108). In this case the benefits are not so palpable. As Sunstein (2007) has pointed out, the Bush administration and much of the US public were prepared to go to great lengths to forestall even a small chance of mass casualty terrorism, but took the possibility of mass casualties from climate change in stride.

Part of the problem, Jamieson argues, lies in human cognition: unlike terrorism, global warming is a complex, slow-motion phenomenon that natural selection did not prepare us to recognize or address effectively. That we do not have the gut-level feeling that climate change is occurring is, in his view, 'the hardest problem to overcome' (p. 103). It is exacerbated by miscommunication between scientists and

(C) 2016 Macmillan Publishers Ltd. 1470-8914 Contemporary Political Theory Vol. 16, 1, 155-157 
laypeople. In an insightful passage, Jamieson notes the difference in the way that laypeople and scientists think about uncertainty. Whereas scientists recognize that even well-established hypotheses entail some uncertainty, in everyday speech saying that a statement is uncertain is equivalent to saying that it lacks grounding: 'if I am uncertain about whether I paid the water bill, then it is natural to think that there is no reason to suppose that I did' (p. 86). Likewise, if a scientist states that it is uncertain whether a given amount of climate change will occur, she means that there may be either less change or more. Laypeople, on the other hand, are apt to assume that the uncertainty operates in one direction - that it will be either this much or less.

Climate-change deniers seize onto and exploit these misunderstandings. While Jamieson often seems to write more in sorrow than in anger, it is clear from his account that the death of the 'Rio dream' was not just a tragedy, but a crime. Powerful vested interests sowed much confusion, notably in the United States. Jamieson cites a 2010 survey showing that 41 per cent of Americans would not be prepared to pay even a single dollar in order to develop renewable energy. This was not just a cognitive failure, but a moral and political one. Whereas the rich would pay the lion's share of the costs of dealing with climate change, the chief beneficiaries would be parties whose interests are poorly represented in contemporary democracies: 'those who live beyond the borders of the major emitters, future generations, animals, and nature' (p. 100). Those familiar with the failure of the rich states to eradicate famine will not be surprised that they have failed to solve climate change.

Much else can be learned from this wide-ranging, well-written book. The discussion of climate economics is particularly good. Jamieson shows a knack for explaining and critiquing key concepts like the discount rate. He notes the inconsistency of discounting the interests of future people because we care less about them, but insisting on equal weight for the interests of all people existing at present. Contemporary Americans care less about losses in the future than the present, but they also care less about losses in other countries. If temporal partiality is justified, why not spatial partiality as well? Discussing the use of risk premiums as a measure of the value of a 'statistical life', Jamieson points out that people only accept such risks 'because some of them falsely believe that they will not die' (p. 132). One can quibble with this formulation - it may be that people correctly believe that they will probably not die - but Jamieson is right to ask whether the value of a life can be properly measured by guesses about the future, some of which will later turn out to be wrong. In contrast, the book's discussion of ethics also makes worthwhile points, but offers fewer insights that will be new to those already familiar with Jamieson's previous work.

What then should we do? Jamieson offers wise if unsurprising advice: Encourage policies with multiple payoffs that will enjoy broader support; judge competing policies on their own merits, without preconceptions about what types of response are best; cultivate virtues such as 'respect for nature'; try to force the pace of technological research and deployment; and give priority to phasing out the use of 
coal. Climate policy will and must involve a mixture of competing national approaches, and '[w]e will have to abandon the Promethean dream of a certain, decisive solution and instead engage with the messy world of climate politics sprawling across jurisdictions'. There are no 'silver bullets' (pp. 220, 238).

Aren't there? I am not so sure. Most deliberate efforts to tackle climate change have failed. Jamieson notes that 'the three main factors that have reduced GHG [greenhouse gas] emissions are, in increasing importance: global recession, the collapse of communism, and China's one child policy' (p. 59). But today, an increasingly important factor is a sharp fall in the cost of alternative energy. Some experts predict that solar energy could become competitive on price with fossil fuels within a decade (King and Layard, 2013). If this occurs, the world will make the energy transition for the same reason we switched to digital technology - the advantages will be palpable even to rich states preoccupied with the short term. If it does not happen, then as the BRICs industrialize, emissions may go through the roof whatever else we do. While we are usually wise not to put all our eggs in one basket, here our best hope may be to concentrate our efforts. We need silver bullets, and we need them soon (Karlsson, 2014).

\section{References}

Karlsson, R. (2014) In Defence of Magic Silver Bullets. Conference paper presented at the Australian Political Studies Association conference, Sydney, 28 September-1 October, http://papers.ssrn.com/sol3/ papers.cfm?abstract_id=2440165, accessed 1 November 2015.

King, D. and Layard, R. (2013) We Must Harness the Power of the Sun. Observer 29 September. Sunstein, C. (2007) Worst-Case Scenarios. Cambridge, MA: Harvard University Press.

Matthew Rendall University of Nottingham, Nottingham NG7 2RD, UK matthew.rendall@nottingham.ac.uk 